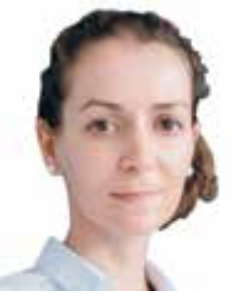

PAXMEEBA Ирина Игоревна

КандиАат эКономических наук, старший преподаватель кафедры региональной, муниципальной экономики и управления

Уральский государственный экономический университет 620144, РФ, г. Екатеринбург, ум. 8 Марта/Народной Воли, 62/45 Tел.: (343) 221-27-76

E-mail: fram_ur@mail.ru

\section{Ключевые слова}

ОЦЕНКА РЕГУЛИРУЮЩЕГО ВОЗДЕЙСТВИЯ (ОРВ)

УПРАВЛЯЕМЫЕ ПАРАМЕТРЫ

РЕГИОНАЛЬНАЯ ЭКОНОМИКА

РЕГУЛЯТОРНАЯ ПОЛИТИКА

\section{Управляемые параметры системы оценки регулирующего воздействия региона}

\section{Аннотация}

Статья посвящена исследованию управляемых параметров функционирования системы оценки регулирующего воздействия (ОРВ) в субъекте РФ. Методологическая база исследования основана на совокупности подходов региональной экономики и неоинституциональной экономической теории. На основе методов системно-структурного и факторного анализа выделен ряд элементов системы ОРВ в субъекте РФ: акторы, организационная структура, предметное поле и методика оценки. Проанализированы содержание и влияние управляемых параметров на качество проведения оценки, функционирование и развитие самой системы ОРВ в целом. В частности, в статье уточнены акторы, структурированы их функциональные роли, их взаимосвязи в субъектах РФ. Предложены перспективные меры управления выявленными параметрами системы ОРВ, в том числе обусловленные цифровизацией экономики. Результаты исследования и предложения автора могут быть использованы в практике органов власти для совершенствования системы ОРВ в субъектах РФ, что в свою очередь будет способствовать формированию благоприятной регуляторной среды и делового климата территорий.

\section{ВВЕДЕНИЕ}

В 1970-е годы представители направления экономического анализа права активно продвигали идею о необходимости ограничения государственного регулирования. В частности, Дж. Бьюкенен предложил использовать инструменты, связывающие правовую и политическую деятельность с экономической теорией. В результате в крупнейших странах Запада (США, Великобритания, Германия) в рамках реформ государственного управления на фоне прихода к власти сторонников неолиберализма и дерегулирования в деятельность государственных служащих внедряются подходы экономического оценивания принимаемых регуляторных решений, или оценка регулирующего воздействия (далее - ОРВ)'

В российскую практику на национальном уровне ОРВ входит с 2010 г. Органы власти субъектов РФ традиционно следуют за федеральным правительством в части подходов к реализации механизмов управления социально-экономическим состоянием, и ОРВ не становится исключением. Однако специфика полномочий, экономическая и политическая дифференциация субъектов РФ накладывают свои ограничения на эффективное управление системой ОРВ в регионах.

Целью работы является формулирование перспективных направлений воздействия на управляемые параметры системы ОРВ в регионе. Задачи статьи: выявление и систематизация управляемых параметров функционирования системы ОРВ на региональном уровне, обоснование их роли и разработка механизмов управления ими.

\section{ОРВ В ФОКУСЕ ИССЛЕДОВАНИЙ РОССИЙСКИХ УЧЕНЫХ}

ОРВ как подход к формированию «умного», взвешенного и сбалансированного по интересам регулирования утвердилась в России на национальном

\footnotetext{
${ }^{1}$ Согласно определению Комитета по регуляторной политике Организации экономического сотрудничества и развития, ОРВ - это процесс определения проблем и целей регулирования, выбора альтернатив достижения этих целей для исключения излишнего и необдуманного регулирования и с использованием научных и поддающихся последующей проверке техник, применимых ко всей имеющейся доступной информации, а также с учетом различных мнений, полученных в ходе консультаций, анализа издержек и выгод выбранных альтернатив (Recommendation of the Council on regulatory policy and governance. P.: OECD Publishing, 2012).
}

JEL classification

KO, P48, R50 


\section{Controlled Parameters of the System for Assessing the Regulatory Impact of a Region}

\section{Abstract}

The paper deals with the controlled parameters of the system for assessing the regulatory impact (RIA) in a federal subject of Russia. The methodological basis of the study is a set of regional economics approaches and neo-institutional economic theory. Based on the methods of system-structural and factor analysis, the author points out a number of elements of the RIA system in a federal subject of Russia: actors, organisational structure, subject field and assessment technique. We analyse the content and effect of the controlled parameters on the quality of assessment, the functioning and the development of the entire RIA system. In particular, the paper specifies the system's actors, clarifies their functional roles and interconnections in federal subjects of Russia. The study develops effective measures for managing the revealed parameters of the RIA system, including those conditioned by digitalisation of economy. The research results and the author's proposals can be useful for government officials to perfect the RIA system in federal subjects of Russia, which, in turn, can contrubute to the formation of a favourable regulatory environment and business climate of a region.

уровне 1 . Об этом свидетельствует неослабевающий интерес к данному инструменту влияния на регуляторную политику со стороны бизнес-сообщества, постоянное расширение специфики анализируемых сторон (выделение в рамках федеральной ОРВ влияния на малый и средний бизнес, на технологическое развитие отечественной экономики и развитие субъектов РФ), формирование отечественных научных коллективов, активно развивающих теорию и методологию экономической оценки права, «умного регулирования». В частности, А. А. Ефремовым [9], Г.3. Мансуровым [22], В.Л. Тамбовцевым [31], Ю.А. Тихомировым [32], И.Д. Тургель [33] исследованы вопросы повышения эффективности нормотворчества благодаря применению ОРВ. Данные исследователи уделяют основное внимание организационным и юридическим аспектам применения ОРВ, не раскрывая в достаточной степени ее экономическую сущность. Влиянию системы ОРВ на экономику территории посвящены работы Ю.В. Шамкова, А.Г. Шеломенцева [36], однако в целом данный вопрос крайне мало раскрыт в научной литературе. Исследования Д.Б. Цыганкова [15; 38], А.Е. Шаститко $[11 ; 21]$, М.С. Шклярук [38] сосредоточены на поиске оптимального государственного регулирования, они наиболее близки к позициям автора с точки зрения признания перспективности ОРВ для формирования умного регулирования, однако отличаются объектом исследования, концентрируясь на федеральном, а не региональном уровне. Предметом авторских исследований становятся особенности функционирования и управления именно региональной системой ОРВ, а также взаимосвязям, возникающим внутри системы.

Выявление и систематизация ключевых параметров системы ОРВ в субъектах РФ служат необходимым условием управления данным объектом. Несмотря на имеющиеся изыскания по вопросу становления ОРВ в субъектах РФ (В.Ф. Баркатунов [2], Н.В. Брюханова [28], А.Б. Дидикин [7], В.В. Колегов [19],

\footnotetext{
${ }^{1}$ На федеральном уровне ОРВ регламентирована постановлением Правительства РФ от 17 декабря 2012 г. № 1318 «О порядке проведения федеральными органами исполнительной власти оценки регулирующего воздействия проектов нормативных правовых актов» и курируется Департаментом оценки регулирующего воздействия Минэкономразвития России. На региональном и муниципальном уровне обязанность проведения ОРВ закреплена Федеральным законом от 2 июля 2013 г. № 176-Ф3; дополнительно приказом Минэкономразвития России от 26 июля 2016 г. № 471 утверждены актуализированные методические рекомендации для органов власти субъектов РФ.
}

Irina I. RAKHMEEVA

Cand. Sc. (Econ.), Sr, Lecturer of Regional \& Municipal Economics and Governance Dept.

Ural State University of Economics 620144, RF, Yekaterinburg, 8 Marta/Narodnoy Voli St., 62/45 Phone: (343) 221-27-76

E-mail: fram_ur@mail.ru
Keywords

REGULATORY IMPACT ASSESSMENT (RIA)

CONTROLLED PARAMETERS

REGIONAL ECONOMY

REGULATORY POLICY
JEL classification

KO, P48, R50 

системы ОРВ.

Работоспособность системы ОРВ определяет качество регуляторной среды в субъекте РФ, что в свою очередь сказывается на инвестиционной привлекательности территории, предпринимательской активности населения и социально-экономическом развитии в целом. Данное положение подтверждается исследованиями ряда ученых, как зарубежных: Г. Беккера [40], Т. Горгенса [42], С. Джейкобса [43], С. Дьянкова [41], К. Льюэллина [44], Р. Познера [45], так и отечественных: Г.Б. Клейнера [17], В. А. Мау [12], А. Ю. Шумакова [30], и является основополагающей идеей данной работы.

Бенефициарам оценки необходимо понимать, какие параметры влияют на развитие системы ОРВ и какое воздействие они могут оказать на нее. При этом под бенефициарами автор понимает как предпринимательское сообщество региона, использующее ОРВ в качестве инструмента легального лоббизма, так и органы власти субъекта РФ, применяющие ОРВ для создания комфортных условий ведения бизнеса на территории региона и налаживания конструктивного взаимодействия с местным сообществом.

\section{СИСТЕМАТИЗАЦИЯ УПРАВЛЯЕМЫХ ПАРАМЕТРОВ СИСТЕМЫ ОРВ СУБЪЕКТА РФ}

Экспликация объекта, представляющего собой управленческую систему, каковой, в частности, является система ОРВ в субъекте РФ, проведена по общепринятым основаниям [4; 10; 14] и включает следующие блоки: акторы и организационная структура системы ОРВ, предмет и методика оценки.

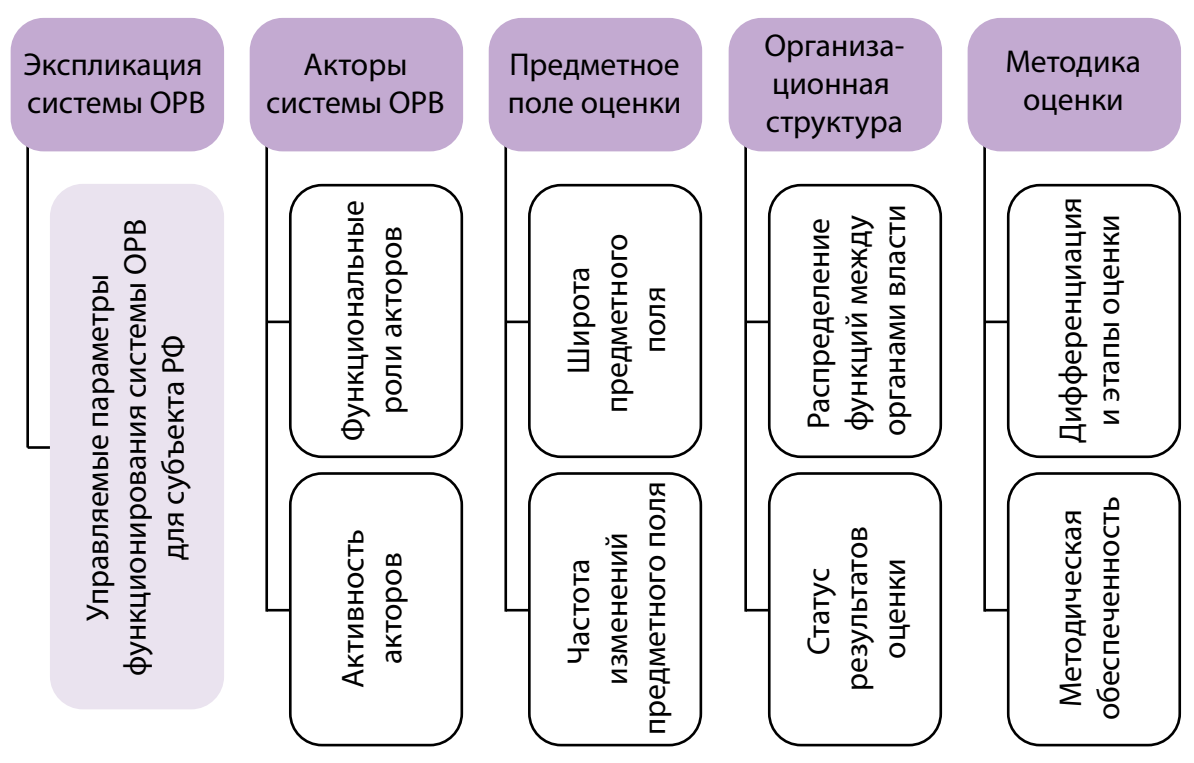

Рис. 1. Систематизация управляемых параметров функционирования системы ОРВ субъекта РФ по основным элементам экспликации
На первом этапе автором установлен подход к систематизации ключевых внутренних, а значит поддающихся управлению, параметров функционирования системы ОРВ на региональном уровне (рис. 1). При этом параметры устанавливаются как управляемые характеристики элементов системы ОРВ. Новизна данного подхода выражается в обобщении параметров, выявленных исследователями региональных систем ОРВ $[2 ; 7 ; 19 ; 28 ; 29 ; 37]$ и автором [25].

Проанализируем содержание управляемых параметров, определяющих функционирование системы ОРВ в субъектах РФ.

1. Функциональные роли и активность всех акторов (рис. 2).

На рис. 2 уточнены акторы системы ОРВ в субъекте РФ и их взаимосвязи. Традиционный подход включает только таких акторов, как органы власти и предпринимательское сообщество $[2 ; 7 ; 15 ; 19 ; 21 ; 28 ; 29 ; 37 ; 38]$, автор предлагает добавить другие группы - население, СМИ, научные и учебные организации.

В таблице в колонке «Возможная активность» представлены крайние случаи соответствующего параметра. Новизной исследования является идея автора оценивать и управлять активностью всех акторов системы ОРВ, поскольку на практике нормативно регулируются и принимаются меры по корректировке эффективности только функциональных ролей органов власти регионального уровня и участников публичных консультаций', т.е. далеко не всех акторов системы и не в полном объеме 2 .

Дискуссионным остается вопрос о положительном или отрицательном влиянии жесткости регулирования системы ОРВ со стороны федеральных органов, а также регионального законодательного органа, устанавливающих границы применимости ОРВ и требований к процедурам.

При ситуации низкой активности и исполнительности государственных служащих в субъектах РФ может требоваться усиленный контроль и меры «подталкивания» в отношении региональных органов власти со стороны вышестоящих фе-

${ }^{1}$ Публичные консультации - неотъемлемый элемент процедуры ОРВ, заключающийся в проведении публичных обсуждений управленческих решений (проектов нормативных правовых актов) органов власти.

${ }^{2}$ В настоящее время активность таких акторов, как органы власти субъекта РФ и участники публичных консультаций, регулируется нормативными правовыми актами различного уровня: федеральными законами, ведомственными приказами федеральных органов, законами и подзаконными актами субъектов РФ. Для управления активностью иных акторов автор предлагает расширить указанные нормативные правовые акты и сформировать перечень дополнительных нормативных и ненормативных документов, что входит в круг полномочий различных исполнительных и представительных органов федерального и регионального уровня. 


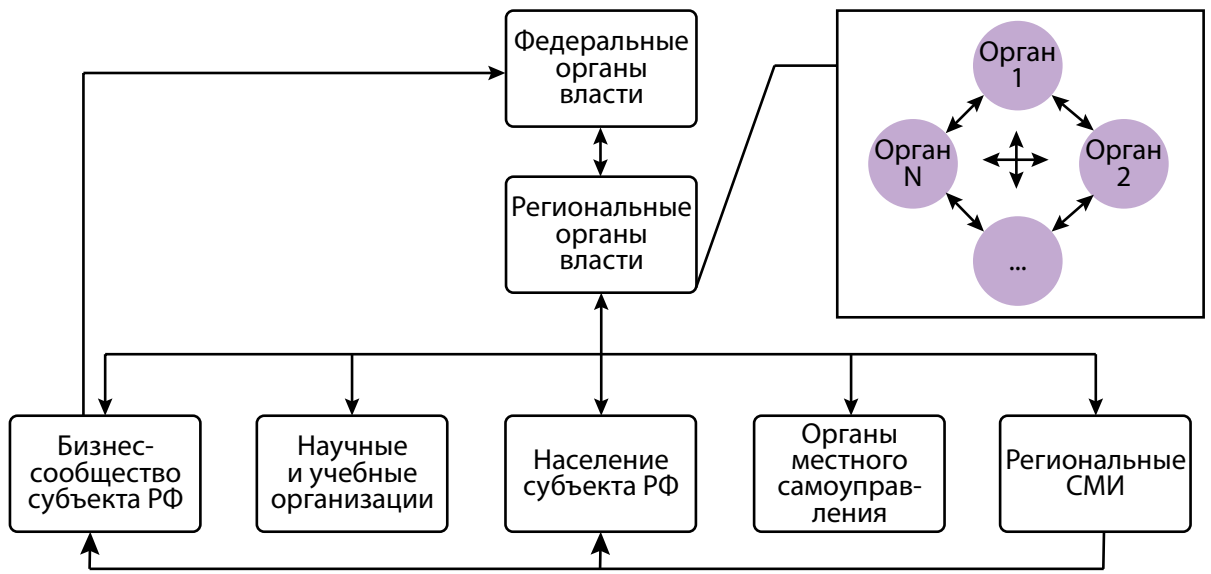

Рис. 2. Акторы системы ОРВ в субъекте РФ и их взаимосвязи
2. Широта и частота изменений предметного поля оценки.

В то время как оптимальность масштабов государственного регулирования является предметом острых дискуссий (например, см. работы К. Санстейна [47], Г. Стиглера [46], Д.Б. Цыганкова, М.С. Шклярук [38] и др.), открытым также остается вопрос, какие сегменты регулирования подвергать оценке.

Предметное поле может опреде- : ляться от установления узких и конкретных сфер, вопросов, подлежащих оценке (подход, выбранный для деральных органов, стимулирующие к выполнению установленных требований по проведению ОРВ.

Вместе с тем, учитывая, что автор описывает направления активности, к которым следует стремиться, в конечном итоге при достижении «идеальной ситуации», предполагающей высокую активность на местах, предлагается оценивать предоставление широких прав субъектам РФ для возможности учета территориальных особенностей как положительное значение, поскольку регионы России обладают высокой дифференциацией потребностей, возможностей и социально-экономических условий.
OРВ на федеральном уровне), до установления общего признака множества нормативных правовых актов, попадающих под ОРВ (подход, установленный для субъектов РФ федеральным законодательством). Минимальные общие требования к предметному полю ОРВ устанавливаются федеральными актами. Вместе с тем органы власти субъекта РФ не ограничены в праве дополнить предметное поле.

Обобщая существующую практику, можно выделить следующие подходы к внедрению и развитию системы OРB с точки зрения динамики предметного поля.

Функциональные роли и активность акторов системы ОРВ субъекта РФ

\begin{tabular}{|c|c|c|c|}
\hline \multirow{2}{*}{ Актор } & \multirow{2}{*}{ Возможные функции } & \multicolumn{2}{|c|}{ Возможная активность } \\
\hline & & негативная & позитивная \\
\hline $\begin{array}{l}\text { Федеральный } \\
\text { законодательный } \\
\text { орган }\end{array}$ & $\begin{array}{l}\text { 1. Установление минимальных требований и границ } \\
\text { системы ОРВ. } \\
\text { 2. Мониторинг и рейтингование субъектов РФ в части } \\
\text { правоприменения законодательства в сфере ОРВ, } \\
\text { развития системы ОРВ }\end{array}$ & $\begin{array}{l}\text { Жесткое } \\
\text { регулирование } \\
\text { субъектов РФ }\end{array}$ & $\begin{array}{l}\text { Предоставление } \\
\text { широких прав } \\
\text { субъектам РФ }\end{array}$ \\
\hline $\begin{array}{l}\text { Федеральный } \\
\text { уполномоченный } \\
\text { исполнительный орган } \\
\text { власти в сфере ОРВ }\end{array}$ & $\begin{array}{l}\text { 1. Методическое сопровождение. } \\
\text { 2. Организационное и техническое сопровождение. } \\
\text { 3. Организация обучения. } \\
\text { 4. Взаимодействие с федеральным законодателем в части } \\
\text { реализации его функций. } \\
\text { 5. Мониторинг и рейтингование субъектов РФ. } \\
\text { 6. Взаимодействие с бизнес-объединениями }\end{array}$ & $\begin{array}{l}\text { Отсутствие помощи } \\
\text { субъектам РФ }\end{array}$ & $\begin{array}{l}\text { Активная } \\
\text { масштабная } \\
\text { помощь субъектам } \\
\text { РФ }\end{array}$ \\
\hline $\begin{array}{l}\text { Уполномоченный } \\
\text { исполнительный орган } \\
\text { власти субъекта РФ } \\
\text { в сфере ОРВ }\end{array}$ & $\begin{array}{l}\text { 1. Нормативное обеспечение функционирования системы } \\
\text { ОРВ региона. } \\
\text { 2. Организационное и техническое обеспечение. } \\
\text { 3. Методическое обеспечение. } \\
\text { 4. Непосредственное участие в процедурах ОРВ. } \\
\text { 5. Контроль за соблюдением установленных правил } \\
\text { проведения ОРВ и взаимодействия акторов системы. } \\
\text { 6. Проведение внутреннего мониторинга уровня развития } \\
\text { системы, формирование отчетности и определение } \\
\text { направлений развития системы. } \\
\text { 7. Информационное сопровождение. } \\
\text { 8. Обеспечение обучения акторов системы. } \\
\text { 9. Обеспечение обратной связи и взаимодействия всех } \\
\text { акторов системы }\end{array}$ & $\begin{array}{l}\text { Пассивность, } \\
\text { закрытость, } \\
\text { отстраненность }\end{array}$ & $\begin{array}{l}\text { Полноценная } \\
\text { и качественная } \\
\text { реализация } \\
\text { своих функций, } \\
\text { инициативность, } \\
\text { открытость }\end{array}$ \\
\hline
\end{tabular}




\begin{tabular}{|c|c|c|c|}
\hline \multirow{2}{*}{ Актор } & \multirow{2}{*}{ Возможные функции } & \multicolumn{2}{|c|}{ Возможная активность } \\
\hline & & негативная & позитивная \\
\hline $\begin{array}{l}\text { Органы власти } \\
\text { субъекта РФ - } \\
\text { разработчики } \\
\text { проектов } \\
\text { нормативных } \\
\text { правовых актов }\end{array}$ & $\begin{array}{l}\text { 1. Непосредственное участие в процедурах ОРВ. } \\
\text { 2. Участие в формировании нормативной базы системы } \\
\text { ОРВ. } \\
\text { 3. Информационное сопровождение. } \\
\text { 4. Обеспечение обратной связи с участниками публичных } \\
\text { консультаций }\end{array}$ & $\begin{array}{l}\text { Формализм, } \\
\text { закрытость, } \\
\text { оппортунизм }\end{array}$ & $\begin{array}{l}\text { Открытость, } \\
\text { инициативность, } \\
\text { качественное } \\
\text { выполнение своих } \\
\text { обязанностей }\end{array}$ \\
\hline $\begin{array}{l}\text { Законодательный } \\
\text { орган субъекта РФ }\end{array}$ & $\begin{array}{l}\text { 1. Установление минимальных требований и границ } \\
\text { системы ОРВ. } \\
\text { 2. Непосредственное участие в процедурах ОРВ }\end{array}$ & $\begin{array}{l}\text { Жесткое } \\
\text { регулирование } \\
\text { исполнительных } \\
\text { органов }\end{array}$ & $\begin{array}{l}\text { Предоставление } \\
\text { широких прав } \\
\text { исполнительным } \\
\text { органам }\end{array}$ \\
\hline $\begin{array}{l}\text { Уполномоченный } \\
\text { по защите прав } \\
\text { предпринимателей } \\
\text { субъекта РФ }\end{array}$ & $\begin{array}{l}\text { 1. Непосредственное участие в процедурах оценки. } \\
\text { 2. Влияние на регуляторную политику и защита } \\
\text { прав предпринимателей путем участия в публичных } \\
\text { консультациях и совещательных органах. } \\
\text { 3. Участие в формировании нормативной базы системы } \\
\text { ОРВ }\end{array}$ & $\begin{array}{l}\text { Пассивная } \\
\text { позиция, } \\
\text { отстраненность } \\
\text { от системы }\end{array}$ & $\begin{array}{l}\text { Реализация всех } \\
\text { доступных функций, } \\
\text { инициативность }\end{array}$ \\
\hline $\begin{array}{l}\text { Органы местного } \\
\text { самоуправления }\end{array}$ & $\begin{array}{l}\text { 1. Участие в процедурах ОРВ. } \\
\text { 2. Влияние на регуляторную политику и защита местных } \\
\text { интересов путем участия в публичных консультациях } \\
\text { и совещательных органах. } \\
\text { 3. Популяризация ОРВ }\end{array}$ & Пассивная позиция & Активная позиция \\
\hline $\begin{array}{l}\text { Предпринимательское } \\
\text { сообщество, в том } \\
\text { числе бизнес- } \\
\text { объединения }\end{array}$ & $\begin{array}{l}\text { 1. Влияние на регуляторную политику и защита своих } \\
\text { интересов путем участия в публичных консультациях } \\
\text { и совещательных органах. } \\
\text { 2. Участие в формировании нормативной базы системы } \\
\text { ОРВ. } \\
\text { 3. Популяризация ОРВ }\end{array}$ & $\begin{array}{l}\text { Пассивная } \\
\text { позиция, } \\
\text { отстраненность } \\
\text { от системы }\end{array}$ & $\begin{array}{l}\text { Реализация всех } \\
\text { доступных функций, } \\
\text { инициативность }\end{array}$ \\
\hline $\begin{array}{l}\text { Научные и учебные } \\
\text { организации }\end{array}$ & $\begin{array}{l}\text { 1. Участие в процедурах оценки. } \\
\text { 2. Участие в формировании нормативной и методической } \\
\text { базы для системы ОРВ. } \\
\text { 3. Формирование компетенций в сфере ОРВ у студентов. } \\
\text { 4. Обеспечение повышения квалификации } \\
\text { государственных служащих по направлению ОРВ. } \\
\text { 5. Мониторинг системы ОРВ по различным параметрам } \\
\text { и выработка рекомендаций для органов власти }\end{array}$ & $\begin{array}{l}\text { Отстраненность } \\
\text { от системы }\end{array}$ & $\begin{array}{l}\text { Реализация всех } \\
\text { доступных функций, } \\
\text { инициативность }\end{array}$ \\
\hline $\begin{array}{l}\text { Население субъекта } \\
\text { РФ, в том числе } \\
\text { союзы потребителей, } \\
\text { профсоюзы }\end{array}$ & $\begin{array}{l}\text { Влияние на регуляторную политику и защита своих } \\
\text { интересов путем участия в публичных консультациях }\end{array}$ & Пассивная позиция & $\begin{array}{l}\text { Реализация } \\
\text { доступных } \\
\text { форм участия } \\
\text { в публичных } \\
\text { консультациях }\end{array}$ \\
\hline СМИ & $\begin{array}{l}\text { 1. Популяризация ОРВ. } \\
\text { 2. Освещение хода разработки и обсуждения общественно } \\
\text { значимых проектов }\end{array}$ & $\begin{array}{l}\text { Отсутствие } \\
\text { интереса } \\
\text { к теме ОРВ } \\
\text { и публикационной } \\
\text { активности }\end{array}$ & $\begin{array}{l}\text { Масштабное } \\
\text { освещение } \\
\text { тематики ОРВ }\end{array}$ \\
\hline
\end{tabular}

Первый подход основан на выборе узкой сферы оценки, а с накоплением практического опыта, развитием организационной и методологической базы предметное поле расширяется.

Второй подход - противоположный: изначально предметное поле определяется широко, а с выявлением реальной потребности, запроса от общественности об участии в формировании регуляторной политики, эффективности приложения сил в различных направлениях предметное поле сужается. Автор считает такой подход наименее эффективным, поскольку он априори предполагает рассеивание ресурсов на начальном этапе на не- производительную оценку и признание неспособности спрогнозировать востребованность и эффективность системы ОРВ на региональном уровне, частичной потери интереса и доверия со стороны участников публичных консультаций.

Третий подход - предметное поле устанавливается с учетом общественно значимых сфер регулирования, под него формируется комплексная организационная, методологическая, ресурсная база. С течением времени предметное поле изменяется только вслед за существенными преобразованиями в экономике региона и страны, изменениями спроса общественности на участие в фор- 
мировании регуляторной политики. Этот подход представляется наиболее эффективным, но трудно реализуемым на практике в силу сложности учета социальных феноменов и инерционности государственного аппарата.

Трансформация предметного поля ОРВ в субъектах РФ (вопросы, подлежащие обязательной оценке), установленного федеральным законодательством, с 2014 по 2017 г. представлена на рис. 3. Минэкономразвития России подготовлен проект по введению дополнительныхисключений из обязательного предметного поля ОРВ, планируемый к внесению в 2018 г. Таким образом, примерно каждые два года происходит изменение предметного поля оценки. Такую частоту автор полагает достаточно адекватной, учитывая динамичность социально-экономических и технологических преобразований.

Итак, на практике наблюдается динамичное сужение предметного поля ОРВ в субъектах РФ, т.е. реализуется второй подход, охарактеризованный автором как наименее эффективный.

\section{3. Организационная структура.}

При описании организационной структуры системы ОРВ в субъекте РФ в первую очередь необходимо установить, каким образом распределяются функции между ключевыми акторами системы - региональными органами власти.

Выделяются три организационные модели распределения функций внутри органов власти субъектов РФ: централизованная, децентрализованная и смешанная $[2 ; 7 ; 19 ; 28 ; 29 ; 33 ; 37]$.

Централизованная модель подразумевает высокую активность и сосредоточение функций непосредственного проведения аналитической работы и публичных консультаций у уполномоченного исполнительного органа власти субъекта РФ. Децентрализованная модель переносит активность по экономическому анализу и взаимодействию с затрагиваемыми регулированием лицами

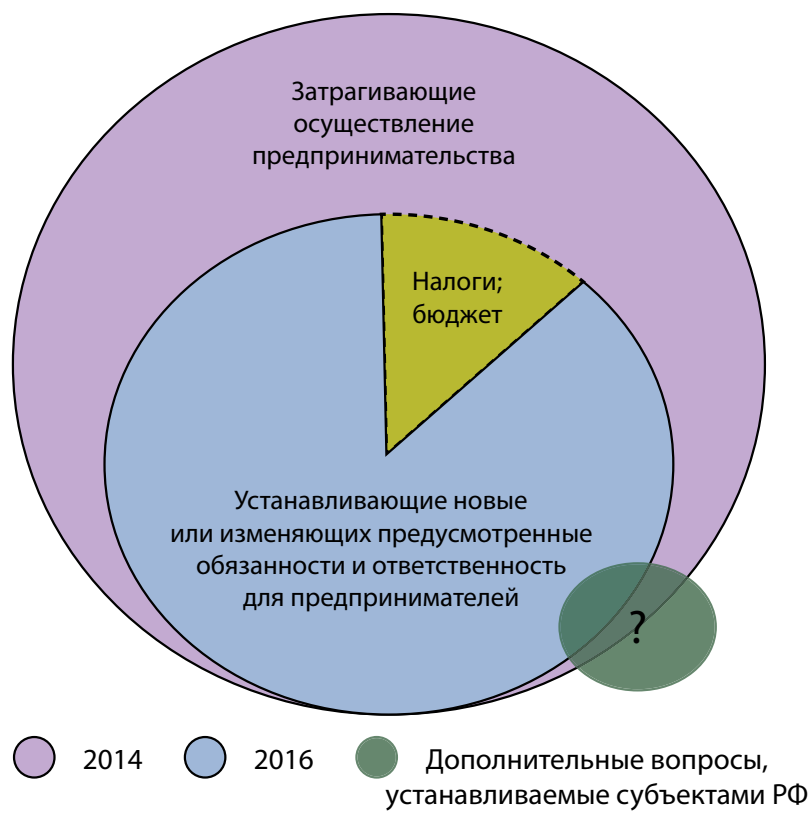

Рис. 3. Нормативно установленные границы предметного поля ОРВ субъектов РФ на органы-разработчики, сохраняя за уполномоченным органом ключевую роль ответственного за качество ОРВ в регионе. Вариации между данными двумя крайними позициями будут являться смешанными моделями.

Также автор включает в организационную структуру системы ОРВ закрепленный статус итогов оценки (заключения об ОРВ), т.е. силу воздействия ОРВ на конечное решение регулятора. Крайними случаями здесь выступают:

- рекомендательный характер ОРВ, когда оценка проводится формально, поступившие от участников публичных консультаций мнения просто принимаются к сведению;

- заградительный статус ОРВ, когда в случае выявления административных барьеров, избыточных издержек, негативного общественного резонанса регуляторная политика подвергается обязательной корректировке.

\section{4. Методика оценки ОРВ.}

Основываясь на современном понимании методики (см.: [3; 8; 23; 39]), автор описывает этапы и сроки ОРВ в зависимости от различных параметров нормативных правовых актов и их проектов.

К управляемым параметрам здесь относится методическая обеспеченность (в первую очередь с точки зрения раскрытия методов и технологий оценки), а также фактическое применение экономических и расчетных методов на практике, применение информационных технологий и баз данных.

Ключевыми методами оценки регулирующего воздействия, применяемыми в российской практике, выступают: анализ издержек и выгод, метод стандартных издержек, анализ эффективности и затрат. Подробнее методы ОРВ изучены в работах М.Е. Глазковой [5], О.В. Козловской [18], В.П. Уманской [34] и других специалистов, также данный вопрос вошел в круг исследований автора $[25 ; 26]$. Отечественными учеными разрабатывается экономический инструментарий для применения ОРВ в отдельных областях права, в частности, для оценки регулирования инновационной деятельности [13; $16 ; 20]$, воздействия на окружающую среду $[1 ; 6 ; 24 ; 35]$, корпоративного законодательства [11], в иных областях регуляторной политики.

\section{ПЕРСПЕКТИВНЫЕ НАПРАВЛЕНИЯ ВОЗДЕЙСТВИЯ НА УПРАВЛЯЕМЫЕ ПАРАМЕТРЫ СИСТЕМЫ ОРВ СУБЪЕКТА РФ}

В условиях перехода России к цифровой экономике, в стремлении государства встать на инновационный курс развития в числе мер по совершенствованию системы ОРВ автор выделяет следующие механизмы, основанные на управлении выявленными параметрами системы ОРВ в субъектах РФ.

1. Управление активностью всех акторов системы ОРВ по направлениям, обозначенным в исследовании. В научной литературе достаточно предложений по повышению эффективности уполномоченных органов в сфере ОРВ и экспертов из бизнес-сообщества (см., например: $[2 ; 7 ; 9$; $19 ; 21 ; 28 ; 29 ; 37])$. Автор предлагает обратить внимание 
на неиспользуемый интеллектуальный ресурс населения, научных и учебных организаций, чей потенциал и интересы не учитываются в большинстве случаев в рамках OPB, а также ресурсы СМИ в части популяризации института ОРВ. Например, могут быть организованы конкурсы студенческих научных работ по проведению экспертизы или оценки фактического воздействия действующих нормативных правовых актов (данное направление оценки как правило, приобретает второстепенное значение на региональном уровне в силу того, что органам власти недостает собственных трудовых ресурсов).

2. Расширение предметной области ОРВ в субъектах РФ путем включения наиболее острых проблемных вопросов для конкретной территории. Для этого региональным уполномоченным органам необходимо на основе социально-экономического анализа состояния субъекта РФ внести соответствующие нормы в законы, регулирующие проведение ОРВ. Так, для приграничных субъектов (Оренбургская, Челябинская и другие области) может быть актуальным обязательное проведение оценки проектов, регулирующих вопросы миграции, не попадающих под ОРВ по формальным основаниям, но оказывающих существенное влияние на рынок труда и развитие экономики.

3. Авторы доклада «Регуляторная политика в России: основные тенденции и архитектура будущего» [27. С. 31] в числе проблем нормотворчества экономически значимых актов выделяют такие как отсутствие связи проектов со стратегическим планированием, неточное целеполагание, недостаточное применение метода стандартных издержек и анализа влияния на малое и среднее предпринимательство. В качестве решения ими предлагается ввести Стандарт доказывания необходимости регулирования.

С учетом результатов проведенного исследования автор считает перспективным иной подход, а именно эволюцию ОРВ в направлении анализа влияния принимаемых управленческих решений на формирование условий для инновационной деятельности и стимулирования применения цифровых технологий, а также разработку новых методов и программных средств для проведения более точной и обоснованной оценки.

Для этого требуется включить соответствующие разделы в формы документов по ОРВ и разработать методические рекомендации по проведению соответствующего анализа. Разовые трудозатраты федерального уполномоченного органа на реализацию данной меры дадут в пер- спективе долгосрочный экономический эффект для всех территорий, выраженный в повышении качества регулирования, создании благоприятных условий для развития перспективных отраслей и технологий.

4. В настоящее время для субъектов РФ предоставлено типовое решение по раскрытию информации о подготовке проектов актов в сети Интернет и проведению публичных консультаций. Ряд регионов пользуется данным решением, иными разработано собственное. Вместе с тем из-за низкого применения на практике количественных методов оценки сохраняется острая потребность именно в автоматизированных программах проведения экономического анализа проектов ввиду отсутствия достаточных компетенций большинства государственных служащих. Например, предоставление программного обеспечения по использованию калькулятора стандартных издержек с возможностью введения в программу индивидуальных региональных исходных данных, разработка программного обеспечения для расчета издержек и затрат с заложенными заранее формулами и методиками для стандартных случаев (введение штрафов, плата за негативное воздействие на окружающую среду и т.д.).

\section{ЗАКЛЮЧЕНИЕ}

Управляя выявленными в исследовании параметрами системы ОРВ субъекта РФ, органы власти и бизнес-сообщество способны существенно влиять на эффективность процедуры оценки, качество взаимодействия друг с другом, способствуя формированию благоприятной, комфортной регуляторной среды для интенсивного развития экономики территории.

Основную роль в решении данной задачи, конечно же, играют исполнительные органы государственной власти субъектов РФ, обладающие ключевыми полномочиями в этой сфере. Представляется перспективным расширение свободы действий региональных органов власти, способных учесть территориальные особенности при планировании деятельности и управлении системой ОРВ.

Учитывая сохранение низкого качества нормотворчества и недостаточную эффективность регулирования, несмотря на многолетнее проведение административной реформы, появление новых вызовов со стороны цифровой экономики и шестого технологического уклада, актуальными представляются не только реализация предложенных рекомендаций, но и поиск новых путей совершенствования регуляторной среды в пространстве региона и методики оценки. .

Библиографическая ссылка: Рахмеева И.И. Управляемые параметры системы оценки регулирующего воздействия региона // Управленец. 2018. T. 9. №5. С. 48-57. DOI: 10.29141/2218-5003-2018-9-5-5.

For citation: Rakhmeeva I.I. Controlled Parameters of the System for Assessing the Regulatory Impact of a Region. Upravlenets - The Manager, 2018, vol. 9, no. 5, pp. 48-57. DOI: 10.29141/2218-5003-2018-9-5-5. 
1. Бальзанников М.И., Евдокимов С.В. Экологическая экспертиза и оценка воздействия на окружающую среду: метод. указания. Самара, 2006.

2. Баркатунов В.Ф., Попов В.В. К вопросу об оценке регулирующего воздействия нормативных правовых актов и управленческих решений (на примере Курской области) // Муниципальная служба: правовые вопросы. 2013. № 2. С. 15-18.

3. Блауг М. Методология экономической науки, или Как экономисты объясняют. М.: Вопросы экономики, 2004.

4. Бухтеева Е.Е. Значение методологии системного подхода в научном исследовании // Новое слово в науке и практике: гипотезы и апробация результатов исследований. 2014. № 14. С. 48-52.

5. Глазкова М.Е., Нанба С.Б. Оценка эффективности действия нормативных правовых актов: современные подходы // Журнал российского права. 2011. № 9. С. 73-80.

6. Данилова Н.В., Каримова С.А. Оценка воздействия на окружающую среду: имплементация международно-правовых требований в российское законодательство // Международное право. 2015. №2. С. 110-121.

7.Дидикин А.Б. Конституционно-правовые аспекты применения оценки регулирующего воздействия проектов законов: федеральный и региональный уровни // Правовые проблемы укрепления российской государственности: сб. ст. Всерос. науч.практ. конф. (29-31 января 2015 г.). Томск: Изд-во Томск. ун-та, 2015. C. 81-82.

8. Дрогобыцкая К.С. Новое в методологии системных исследований // Вестник Оренбургского государственного университета. 2009. № 8. C. 37-42.

9. Ефремов А.А. Оценка регулирующего воздействия в системе институтов повышения эффективности нормотворчества // Вопросы государственного и муниципального управления. 2012. №2. С. 121-133.

10. Зарнадзе А.А. Об основах целостной методологии управления социально-экономическими системами // Экономическая наука современной России. 2008. № 1. С. 114-115.

11. Использование оценок регулирующего воздействия для совершенствования корпоративного законодательства / С.Б. Авдашева и др.; под ред. Р.А. Кокорева, А.Е. Шаститко. М.: Теис, 2006.

12. Институциональные предпосылки современного экономического роста / В.А. Мау, К.Э. Яновский, С.В. Жаворонков, Д.Ю. Маслов. М.: Ин-т экономики переход. периода, 2007.

13. Кайль Я.Я., Епинина В.С. Отечественный и зарубежный опыт совершенствования государственного менеджмента в условиях инновационного развития экономики // Управление экономическими системами: электрон. науч. журн. 2013. № 10.

14. Караваев Н.Л. К особенностям методологии системных исследований // Вестник Вятского государственного гуманитарного университета. 2015. №6. С. 13-17.

15. Карпова П.Г., Цыганков Д.Б. Советы по оптимизации регулирования как неотъемлемый компонент «smart regulation» // Вопросы государственного и муниципального управления. 2012. №3. C. 5-34.

16. Киселев С.В., Гилязутдинова И.В., Дерман Д.О. Государственное регулирование инновационного развития сферы рыночных услуг: методологические подходы к оценке регулирующего воздействия // Экономика и предпринимательство. 2014. №6. С. 253-261.

17. Клейнер Г.Б. Предпринимательский сектор в экономике и обществе: миссия и проблемы ее реализации // Экономическая наука современной России. 2001. №2. С. 46-59.

18. Козловская О.В., Эльмурзаева Р.А. Возможности применения логико-структурного подхода при оценке регулирующего воздействия // Вестник Томского государственного университета. 2013. №366. С. 105-109.
19. Колегов В.В. Особенности институционализации оценки регулирующего воздействия на региональном уровне. Опыт внедрения в Москве // Вопросы государственного и муниципального управления. 2013. №2. С. 127-146.

20. Коломиец Т.И. Развитие института оценки государственного регулирующего воздействия на процессы инновационной деятельности в России // Вестник Томского государственного университета. Экономика. 2013. № 1. С. 19-29.

21. Крючкова П.В., Шаститко А.Е. Оценка регулирующего воздействия и модернизация системы государственного регулирования // Общественные науки и современность. 2006. № 4. С. 21-31.

22. Мансуров Г.3. Экономический анализ права: некоторые современные проблемы // Право и экономика. 2009. № 1. С. 125-126.

23. Манушин Д.В. Уточнение понятия «Методология» // Международный бухгалтерский учет. 2016. № 16. С. 41-60.

24. Пахомова Н., Рихтер К. Экономический анализ экологического права // Вопросы экономики. 2003. № 10. С. 34-49.

25. Рахмеева И.И. Оценка регулирующего воздействия в регионе: инструменты повышения доверия к власти // Вестник Сибирского университета потребительской кооперации. 2017. № 4. C. 30-34.

26. Рахмеева И.И. Оценка экономической эффективности регулирующего воздействия типовых проектов нормативных правовых актов // Оценка регулирующего воздействия и регуляторная политика / под общ. ред. И.Д. Тургель. М.: ИНФРА-М, 2018.

27. Регуляторная политика в России: основные тенденции и архитектура будущего / А.Е. Голодникова, А.А. Ефремов, Д.В. Соболь и др. М.: Высшая школа экономики, 2018.

28. Руденко А.М., Брюханова Н.В. Оценка регулирующего воздействия: современное состояние, проблемы и перспективы применения процедуры в субъектах РФ // Сибирская финансовая школа. 2012. № 6(95). С. 64-69.

29. Сарычева Н.Н. Оценка регулирующего воздействия в регионах России. Текущая ситуация и пути развития // Государственное управление. Электронный вестник. 2016. № 56. С. 168-193.

30. Согласование социальных, экологических и экономических интересов - основа сбалансированного развития территориальных систем / Г.Н. Пряхин, А.Ю. Шумаков, Л.В. Костарева и др. // Управление сбалансированным развитием территориальных систем: вопросы теории и практики. Челябинск: Челябинск. гос. ун-т, 2016. C. 198-223.

31. Тамбовцев В.Л. Право и экономическая теория. М.: ИНФРА-М, 2005.

32. Тихомиров Ю.А. Регулирующее воздействие: методики и опыт. М.: Юриспруденция, 2016.

33. Тургель И.Д., Вейберт С.И. Институт оценки регулирующего воздействия в странах СНГ: комплексный анализ. Екатеринбург: Урал. ин-т управления РАНХиГС, 2015.

34. Уманская В.П. Технология оценки регулирующего воздействия правовых актов // Административное право и процесс. 2013. № 4. C. 11-14.

35. Худанян Я.Д. Совершенствование правового регулирования оценки воздействия на окружающую среду (на примере Великобритании) // Минеральные ресурсы России. Экономика и управление. 2015. № 1. С. 75-77.

36. Шеломенцев А.Г., Дорошенко С.В., Шамков Ю.В. Оценка регулирующего воздействия как механизм защиты экономических интересов России в условиях ВТО // Бизнес, менеджмент и право. 2013. № 1. С. 29-32.

37. Шестоперов О.М., Смирнов С.В. О ходе внедрения оценки регулирующего воздействия в субъектах РФ: некоторые итоги мониторинга // Вопросы государственного и муниципального управления. 2013. № 2. С. 65-82. 
38. Шклярук М.С., Цыганков Д.Б. Перезагрузка матрицы: как избавить бизнес и общество от ненужных правил // PБK. URL: http:// www.rbc.ru/opinions/economics/26/09/2017/59ca24239a7947371d0 $80 \mathrm{a} 9 \mathrm{~b}$.

39. A Design Science Research Methodology for Information Systems Research / K. Peffers, T. Tuunanen, M.A. Rothenberger, S. Chatterjee // Journal of Management Information Systems. 2007. Vol. 24. Iss. 3. P. 45-77. DOI: $10.2753 / \mathrm{mis} 0742-1222240302$.

40. Becker G. S. Crime and Punishment: An Economic Approach // Journal of Political Economy. 1968. №76(2). P. 169-217. DOI: 10.1086/259394.

41. Djankov S., McLiesh C., Ramalho R.M. Regulation and growth // Economic Letters. 2006. Vol. 92. Iss. 3. P. 395-401. DOI: 10.1016/j.econlet.2006.03.021.

42. Gorgens T., Paldam M., Wuertz A. How Does Public Regulation Affect Growth? Economics Working Paper No. 2003-14.

43. Jacobs S. The RIA revolution // The Hindu Business Line. 2015. November.

44. Llewellyn K. N. The Effect of Legal Institutions upon Economics // American Economic Review. 1925. Vol. 15. № 4. P. 665-683.

45. Posner R.A. Economic Analysis of Law. N.Y.: Wolters Kluwer for Aspen Publishers, 2007.

46. Stigler G.J. The Theory of Economic Regulation // Bell Journal of Economics and Management Science. 1971. Vol. 2. № 1. P. 3-21. DOI: $10.2307 / 3003160$.

47. Sunstein C.R. After the Rights Revolution Reconceiving the Regulatory State. Cambridge, MA: Harvard University Press, 1990.

\section{References}

1. Balzannikov M.I., Yevdokimov S.V. Ekologicheskaya ekspertiza i ot senka vozdeystviya na okruzhayushchuyu sredu [Environmental assessment and environmental impact assessment]. Samara, 2006.

2. Barkatunov V.F., Popov V.V. K voprosu ob otsenke reguliruyushchego vozdeystviya normativnykh pravovykh aktov i upravlencheskikh resheniy (na primere Kurskoy oblasti) [On the issue of regulatory impact assessment of regulatory legal acts and management decisions (the case of Kursk region)]. Munitsipalnaya s/uzhba: pravovye voprosy - Municipal Service: Legal Issues, 2013, no. 2, pp. 15-18.

3. Blaug M. Metodologiya ekonomicheskoy nauki, ili Kak ekonomisty obyasnyayut [The methodology of economics, or how economists explain]. Moscow: Voprosy ekonomiki, 2004.

4. Bukhteeva Ye.Ye. Znachenie metodologii sistemnogo podkhoda $v$ nauchnom issledovanii [The importance of the methodology of the system approach in scientific research]. Novoe slovo $\mathrm{v}$ nauke i praktike: gipotezy i aprobatsiya rezultatov issledovaniy - Advance in Science and Practice: Hypotheses and Application of Results and Research, 2014, no. 14 , pp. 48-52.

5. Glazkova M.Ye., Nanba S.B. Otsenka effektivnosti deystviya normativnykh pravovykh aktov: sovremennye podkhody [Evaluation of the effectiveness of normative legal acts: modern approaches]. Zhurnal rossiyskogo prava - Journal of Russian Law, 2011, no. 9, pp. 73-80.

6. Danilova N.V., Karimova S.A. Otsenka vozdeystviya na okruzhayushchuyu sredu: implementatsiya mezhdunarodno-pravovykh trebovaniy $\mathrm{v}$ rossiyskoe zakonodatelstvo [Environmental impact assessment: implementation of international legal requirements into Russian legislation]. Mezhdunarodnoe pravo - International Law, 2015, no. 2, pp. 110-121.

7. Didikin A.B. [Constitutional and legal aspects of the application of regulatory impact assessment of draft laws: Federal and regional levels]. Pravovye problemy ukrepleniya rossiyskoy gosudarstvennosti: sb. st. Vseros. nauch.-prakt. konf. (29-31 yanvarya 2015 g.) [Proc. of All-Russia sci.-pract. conf. "Legal Problems of Strengthening the Russian nationhood. January 29-31, 2015]. Tomsk: Tomsk univ., 2015. Pp. 81-82.
8. Drogobytskaya K.S. Novoe v metodologii sistemnykh issledovaniy [New in system research methodology]. Vestnik Orenburgskogo gosudarstvennogo universiteta - Bulletin of Orenburg State University, 2009, no. 8, pp. 37-42.

9. Yefremov A.A. Otsenka reguliruyushchego vozdeystviya $v$ sisteme institutov povysheniya effektivnosti normotvorchestva [Regulatory impact assessment in the system of institutions to improve the efficiency of rule-making]. Voprosy gosudarstvennogo i munitsipalnogo upravleniya - Public Administration Issues, 2012, no. 2, pp. 121-133.

10. Zarnadze A.A. Ob osnovakh tselostnoy metodologii upravleniya sotsialno-ekonomicheskimi sistemami [On the basics of holistic management methodology in socio-economic systems]. Ekonomicheskaya nauka sovremennoy Rossii - Economics of Contemporary Russia, 2008, no. 1, pp. 114-115.

11. Avdasheva S.B. et al. Ispolzovanie otsenok reguliruyushchego vozdeystviya dlya sovershenstvovaniya korporativnogo zakonodatelstva [Use of regulatory impact assessments to improve corporate legislation]. Kokoreva R.A., Shastitko A.Ye. (eds.). Moscow: Teis, 2006.

12. Mau V.A., Yanovskiy K.Ye., Zhavoronkov S.V., Maslov D.Yu. Institutsionalnye predposylki sovremennogo ekonomicheskogo rosta [Institutional prerequisites for modern economic growth]. Moscow: In-t ekonomiki perekhod. perioda, 2007.

13. Kayl Ya.Ya., Yepinina V.S. Otechestvennyy i zarubezhnyy opyt sovershenstvovaniya gosudarstvennogo menedzhmenta v usloviyakh innovatsionnogo razvitiya ekonomiki [Domestic and foreign experience of improving public management in the conditions of innovative development of the economy]. Upravlenie ekonomicheskimi sistemami - Management of Economic Systems, 2013, no. 10.

14. Karavaev N.L. K osobennostyam metodologii sistemnykh issledovaniy [The features of the methodology of system research]. Vestnik Vyatskogo gosudarstvennogo gumanitarnogo universiteta - Herald of Vyatka State University, 2015, no. 6, pp. 13-17.

15. Karpova P.G., Tsygankov D.B. Sovety po optimizatsii regulirovaniya kak neotmlemyy komponent «smart regulation» [Tips for optimizing regulation as an integral component of «smart regulation»]. Voprosy gosudarstvennogo i munitsipalnogo upravleniya - Public Administration Issues, 2012, no. 3, pp. 5-34.

16. Kiselev S.V., Gilyazutdinova I.V., Derman D.O. Gosudarstvennoe regulirovanie innovatsionnogo razvitiya sfery rynochnykh uslug: metodologicheskie podkhody $k$ otsenke reguliruyushchego vozdeystviya [State regulation of innovative development of market services: methodological approaches to regulatory impact assessment]. Ekonomika i predprinimatelstvo - Journal of Economy and Entrepreneurship, 2014, no. 6, pp. 253-261.

17. Kleyner G.B. Predprinimatelskiy sektor $v$ ekonomike i obshchestve: missiya i problemy ee realizatsii [Business sector in the economy and society: mission and problems of its implementation]. Ekonomicheskaya nauka sovremennoy Rossii - Economics of Contemporary Russia, 2001, no. 2, pp. 46-59.

18. Kozlovskaya O.V., Elmurzaeva R.A. Vozmozhnosti primeneniya logiko-strukturnogo podkhoda pri otsenke reguliruyushchego vozdeystviya [The possibility of applying the logical-structural approach in the regulatory impact assessment]. Vestnik Tomskogo gosudarstvennogo universiteta - Tomsk State University Journal, 2013, no. 366, pp. 105-109.

19. Kolegov V.V. Osobennosti institutsionalizatsii otsenki reguliruyushchego vozdeystviya na regionalnom urovne. Opyt vnedreniya $\checkmark$ Moskve [Peculiarities of institutionalization of regulatory impact assessment at the regional level. The experience of implementation in Moscow]. Voprosy gosudarstvennogo i munitsipalnogo upravleniya Public Administration Issues, 2013, no. 2, pp. 127-146.

20. Kolomiets T.I. Razvitie instituta otsenki gosudarstvennogo reguliruyushchego vozdeystviya na protsessy innovatsionnoy deyatelnosti $v$ Rossii [Development of the Institute of state regulatory impact assessment on innovation processes in Russia]. Vestnik Tomskogo gosudarstvennogo universiteta - Tomsk State University Journal, 2013, no. 1, pp. 19-29. 
21. Kryuchkova P.V., Shastitko A.Ye. Otsenka reguliruyushchego vozdeystviya i modernizatsiya sistemy gosudarstvennogo regulirovaniya [Regulatory impact assessment and modernization of the state regulation system]. Obshchestvennye nauki i sovremennost - Social Sciences and Contemporary World, 2006, no. 4, pp. 21-31.

22. Mansurov G.Z. Ekonomicheskiy analiz prava: nekotorye sovremennye problem [Economic analysis of law: some modern problems]. Pravo i ekonomika - Law and Economy, 2009, no. 1, pp. 125-126.

23. Manushin D.V. Utochnenie ponyatiya «Metodologiya» [Clarification of the concept «Methodology»]. Mezhdunarodnyy bukhgalterskiy uchet - International Accounting, 2016, no. 16. pp. 41-60.

24. Pakhomova N., Rikhter K. Ekonomicheskiy analiz ekologicheskogo prava [Economic analysis of environmental law]. Voprosy ekonomiki-Issues of Economy, 2003, no. 10, pp. 34-49.

25. Rakhmeeva I.I. Otsenka reguliruyushchego vozdeystviya v regione: instrumenty povysheniya doveriya k vlasti [Regulatory impact assessment in the region: tools to increase confidence in the authorities]. Vestnik Sibirskogo universiteta potrebitelskoy kooperatsii - Journal of Siberian University of Consumer Cooperation, 2017, no. 4, pp. 30-34.

26. Rakhmeeva I.I. [Assessment of the economic efficiency of the regulatory impact of standard draft regulations]. In: Turgel I.D. (ed.). Otsenka reguliruyushchego vozdeystviya i regulyatornaya politika [Regulatory impact assessment and regulatory policy. Moscow: Infra-Moscow, 2018.

27. Golodnikova A.Ye., Yefremov A.A., Sobol D.V. et al. Regulyatornaya politika $v$ Rossii: osnovnye tendentsii $i$ arkhitektura budushchego [Regulatory policy in Russia: main trends and architecture of the future]. Moscow: Vysshaya shkola ekonomiki, 2018.

28. Rudenko A.M., Bryukhanova N.V. Otsenka reguliruyushchego vozdeystviya: sovremennoe sostoyanie problemy i perspektivy primeneniya protsedury $v$ subektakh RF [Regulatory impact assessment: current state of the problem and prospects of application of the procedure in the subjects of the Russian Federation]. Sibirskaya finansovaya shkola - Siberian Financial School, 2012, no. 6(95), pp. 64-69.

29. Sarycheva N. N. Otsenka reguliruyushchego vozdeystviya v regionakh Rossii. Tekushchaya situatsiya i puti razvitiya [Regulatory impact assessment in Russian regions. The current situation and ways of development]. Gosudarstvennoe upravlenie. Elektronnyy vestnik - Public Administration E-Journal, 2016, no. 56, pp. 168-193.

30. Pryakhin G.N., Shumakov A.Yu., Kostareva L.V. et al. [Coordination of social, environmental and economic interests is the basis for balanced development of territorial systems]. In: Upravlenie sbalansirovannym razvitiem territorialnykh sistem: voprosy teorii i praktiki [Managing the balanced development of territorial systems]. Chelyabinsk: Chelyabinskiy gosudarstvennyy universitet, 2016. Pp. 198-223.

31. Tambovtsev V.L. Pravo i ekonomicheskaya teoriya [Law and economic theory]. Moscow: INFRA-M, 2005.

32. Tikhomirov Yu.A. Reguliruyushchee vozdeystvie: metodiki i opyt [Regulatory impact: methods and experience]. Moscow: Yurisprudentsiya, 2016.

33. Turgel I.D., Veybert S.I. Institut otsenki reguliruyushchego vozdeystviya $v$ stranakh SNG: kompleksnyy analiz [Institute for regulatory impact assessment in CIS countries: comprehensive analysis]. Yekaterinburg: Uralskiy institut upravleniya, RANKhiGS, 2015.
34. Umanskaya V.P. Tekhnologiya otsenki reguliruyushchego vozdeystviya pravovykh aktov [Technology of regulatory impact assessment of legal acts]. Administrativnoe pravo i protsess - Administrative Law and Procedure, 2013, no. 4, pp. 11-14.

35. Khudanyan Ya.D. Sovershenstvovanie pravovogo regulirovaniya otsenki vozdeystviya na okruzhayushchuyu sredu (na primere Velikobritanii) [Improvement of legal regulation of environmental impact assessment (the case of the United Kingdom)]. Mineralnye resursy Rossii. Ekonomika i upravlenie - Russia's Mineral Resources. Economics and Management, 2015, no. 1, pp. 75-77.

36. Shelomentsev A.G., Doroshenko S.V., Shamkov Yu.V. Otsenka reguliruyushchego vozdeystviya kak mekhanizm zashchity ekonomicheskikh interesov Rossii v usloviyakh VTO [Regulatory impact assessment as a mechanism to protect Russia's economic interests in the WTO]. Biznes, menedzhment i pravo - Business, Management and Law, 2013, no. 1, pp. 29-32.

37. Shestoperov O.M., Smirnov S.V. O khode vnedreniya otsenki reguliruyushchego vozdeystviya $v$ subektakh RF: nekotorye itogi monitoringa [On the implementation of regulatory impact assessment in the subjects of the Russian Federation: some results of the monitoring]. Voprosy gosudarstvennogo i munitsipalnogo upravleniya - Public Administration Issues, 2013, no. 2, pp. 65-82.

38. Shklyaruk M.S., Tsygankov D.B. Perezagruzka matritsy: kak izbavit biznes i obshchestvo ot nenuzhnykh pravil [Reloading the matrix: how to wean business and society off unnecessary rules]. Available at: http://www.rbc.ru/opinions/economics/26/09/2017/59ca24239a7 947371d080a9b.

39. Peffers K., Tuunanen T., Rothenberger M.A., Chatterjee S. A Design Science Research Methodology for Information Systems Research. Journal of Management Information Systems, 2007, vol. 24(3), pp. 45-77. DOI: 10.2753/mis0742-1222240302.

40. Becker G.S. Crime and Punishment: An Economic. Approach Journal of Political Economy, 1968, vol. 76(2), pp. 169-217. DOI: 10.1086/259394.

41. Djankov S., McLiesh C., Ramalho R.M. Regulation and growth. Economic Letters, 2006, vol. 92, no. 3, pp. 395-401. DOI: 10.1016/j. econlet.2006.03.021.

42. Gorgens T., Paldam M., Wuertz A. How Does Public Regulation Affect Growth? Economics Working Paper No. 2003-14.

43. Jacobs S. The RIA revolution. The Hindu Business Line, 2015 (November).

44. Llewellyn K.N. The Effect of Legal Institutions upon Economics. American Economic Review, 1925, vol. 15, no. 4, pp. 665-683.

45. Posner R.A. Economic Analysis of Law. N.Y.: Wolters Kluwer for Aspen Publishers, 2007.

46. Stigler G.J. The Theory of Economic Regulation. Bell Journal of Economics and Management Science, 1971, vol. 2, no. 1, pp. 3-21. DOI: $10.2307 / 3003160$

47. Sunstein C.R. After the Rights Revolution Reconceiving the Regulatory State. Cambridge, MA: Harvard University Press, 1990. 